\title{
Template-Free Fabrication of Hexagonal ZnO Microprism with an Interior Space
}

\author{
Shi-Yong Yu, Hong-Jie Zhang*, Ze-Ping Peng, Li-Ning Sun, Wei-Dong Shi
}

\section{E-Mail: hongjie@ns.ciac.jl.cn.}

Key Laboratory of Rare Earth Chemistry and Physics, Changchun Institute of Applied Chemistry, Chinese Academy of Sciences, Changchun 130022, P. R. China, and Graduate School of the Chinese Academy of Sciences, Beijing, P. R. China.

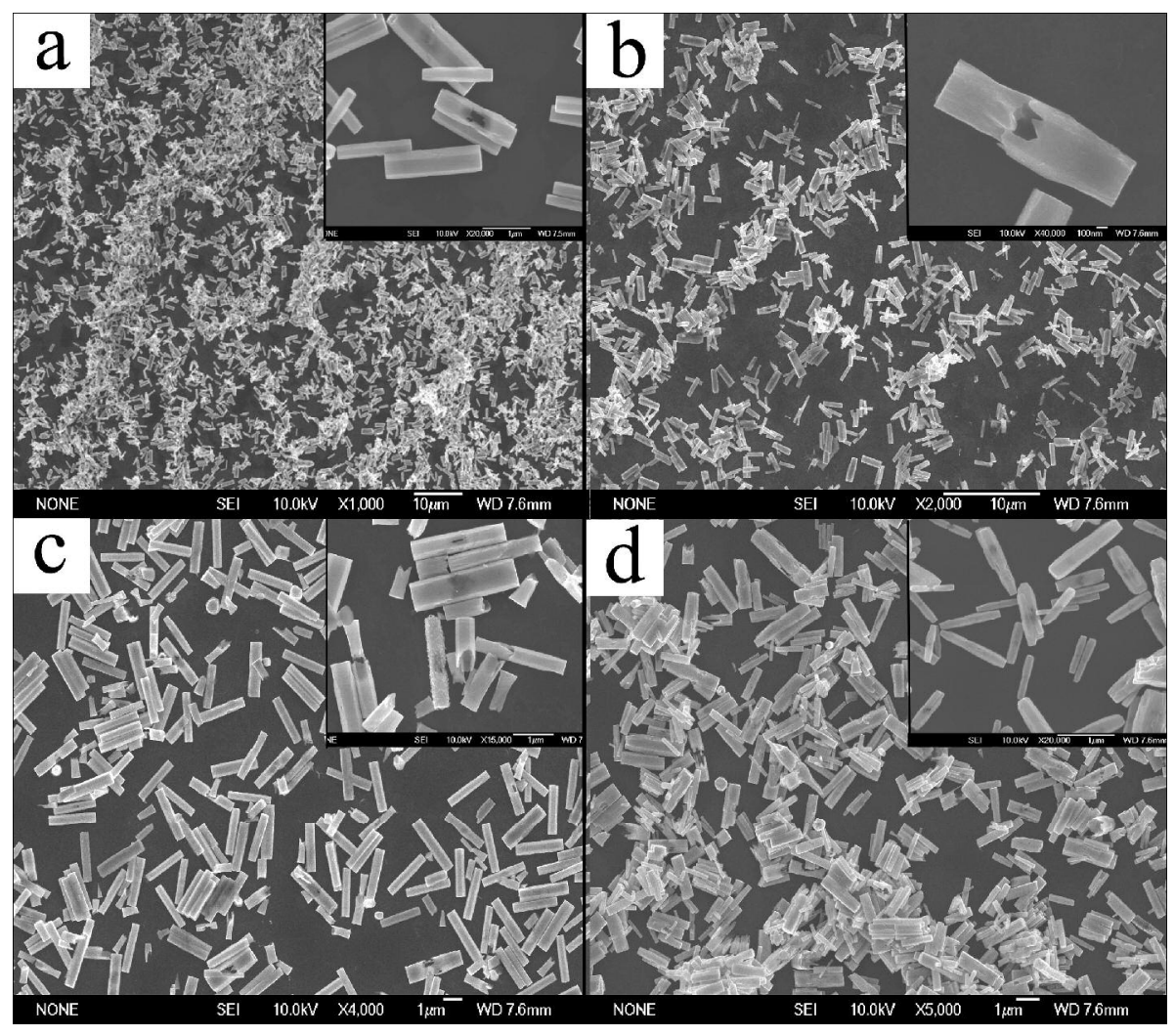

Figure S1. FE-SEM images of $\mathrm{ZnO}$ particles at different temperature: (a) $150{ }^{\circ} \mathrm{C}$, (b) $160{ }^{\circ} \mathrm{C}$, (c) $180{ }^{\circ} \mathrm{C}$, and (d) $200{ }^{\circ} \mathrm{C}$. Insets in the images are the corresponding high-magnification SEM micrographs. 


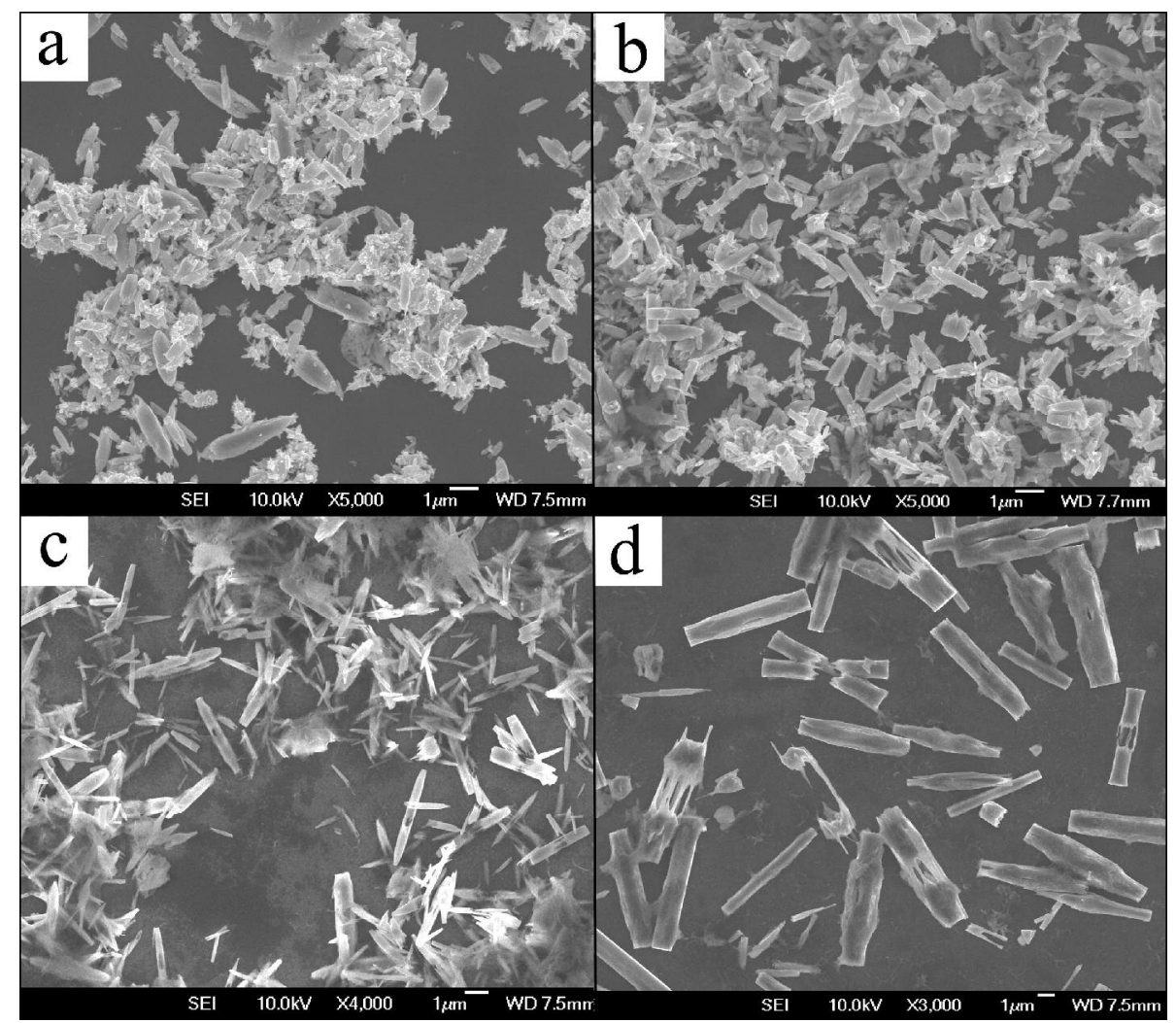

Figure S2. Synthesis performed under the standard conditions but changing the concentration of ammonia to: (a) $0.27 \mathrm{~mol} / \mathrm{L}$, (b) $0.54 \mathrm{~mol} / \mathrm{L}$, (c) $0.79 \mathrm{~mol} / \mathrm{L}$, and (d) $1.27 \mathrm{~mol} / \mathrm{L}$. 


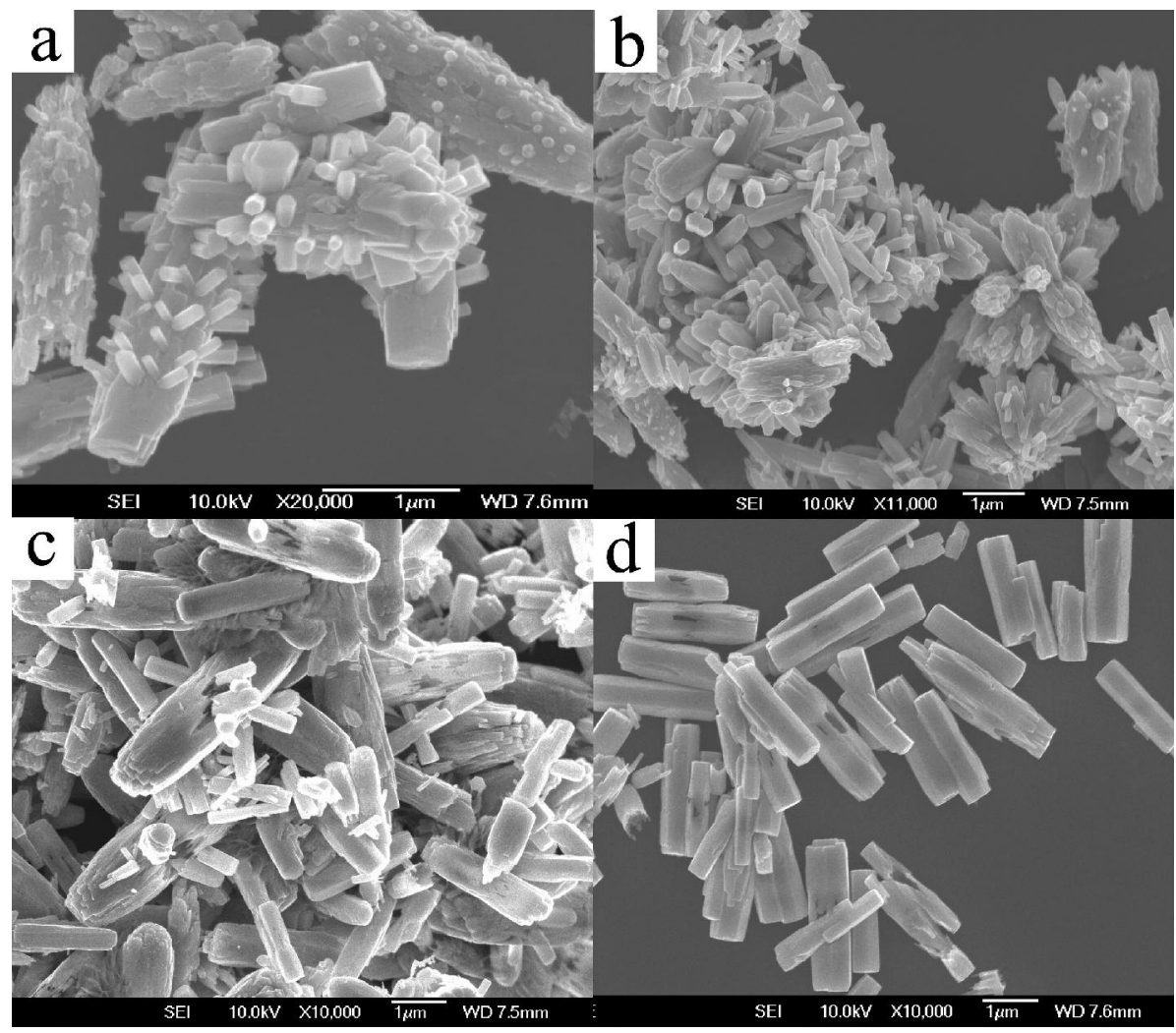

Figure S3. FE-SEM images of the $\mathrm{ZnO}$ nanoparticles synthesized under standard conditions in mixed solution with different volume ratios of $\mathrm{V}_{\mathrm{W}}: \mathrm{V}_{\mathrm{E}}=$ (a) 1:4, (b) 2:3, (c) 3:2, and (d) 4:1. 